it does in the air. In such circumstances there would be no collisions. Ships would proceed with much more caution than they do now and they would certainly be controlled from shore in all congested areas. Possibly therefore, if I may dare to say so, radar designers would do better to think of ergonomics, the ideal display and absolute reliability than to lavish their talents on complex anti-collision systems that will always seem more effective in the classroom than on the sea. Finally, there is an evident need for more radar softwear. Radar training afloat would be a great deal more effective than it can ever be ashore and supertankers are large enough to accommodate a school.

\title{
Radar at Sea
}

\section{H. L. Lubin}

As one of the authors of Marine Radar and How to Use It which was reviewed by Captain Cockcroft in the October 1971 issue of this Journal I feel it necessary to reply to some of his comments. Though he and I may disagree on a few points the authors can only be pleased to have had someone so well known take the time and effort to review our book.

In discussing radar interference he quotes our comment that it is comforting to know that a radar-equipped ship has the equipment operating, and adds 'Unfortunately this cannot be relied upon as the interference may be caused by a vessel at greater range.' But we went on to say '. . . with a radar set that is operating and hopefully being intelligently used'. How far away the other ship is wasn't the point at all. The objective was to indicate that one will see radar interference on his own scope now and then and that is not to be relied upon as an indication of some sort of intelligent analysis at its source.

Paragraph four of the review is a bit misleading in itself. We do recommend gyro-stabilized relative motion plotting and the use of the reflection plotter. The problem exercises were certainly presented as manœuvring board solutions as we could see no other way to indicate the solution procedures in the book. But '. . . plotted at the centre' was only part of the instruction material, and to get the reader through the basics to the 'off centre' method proposed to be used on the reflection plotter in real life.

The real cause for comment is based on the review from paragraph five onwards. Though the book was basically a joint effort, the collision avoidance chapter was my own and the comments to follow are mine.

The Rules have, no doubt, been memorized by every seafarer who has been one for any length of time. Even in his cups, he will be able to quote any rule you ask for verbatim. When it comes to acting on these rules, however, the difference between how clear they are and how precise they are begins to take its toll. Whether we are privileged or burdened, i.e. we can see each other (and what if only one of us sees the other ?), or whether we have been radar-watching each other, begins under the Rules to complicate the sailor's life. Whether Rule 21 or $16(\mathrm{c})$ applied is (pardon the heresy) begging the point. The vital object of any of the Rules-is to prevent a collision and further, in my opinion, to preclude even the risk of one. 
Perhaps I should have used a few more words-as when discussing a potential collision I assumed, but did not actually state, collision relative motion to be o miles C.P.A. as shown in Figs. 45,47 and 48 and stated at page 94. How else could one make the categoric statement: 'This will always increase the minimum distance and reduce the relative speed. ...' Turning right will only do this always when the relative motion from the port side is, and has been, collision (o miles C.P.A. relative motion).

The major difference between Captain Cockcroft and me is probably over where (or when) the 'danger of collision' really begins to exist. With due deference to Lord Esher, in today's arena I take issue with the third sentence of his findings as quoted: 'Nobody could seriously contend that if two ships are 6 miles apart the Regulations for Preventing Collisions are applicable to them.' In those days he may well have been right. Even Captain Cockcroft adds: 'Modern vessels proceed at greater speed, but action taken at 10 miles is unlikely to cause danger of collision.'

My whole hypothesis is not that action taken at 10 miles (or 6) is likely to cause any danger of collision, but rather that inactivity very well may-at no matter what distance. Not having done something at 10 miles (or 8 or 6 or 4), may, with modern vessels, be sealing someone's doom.

Does the sea-going community really feel that steady true bearing on another vessel, from 10 or 12 miles down to say 5 or 6 , whether visual or radar does not indicate risk of collision and 'immediate' danger? Captain Cockcroft says 'Rule 27 only permits a departure in order to avoid immediate danger'. This is where I find the Rules clear but not precise. When is the danger 'immediate'? This is the old problem of judgment as to when the collision (obviously assuming there may be one) cannot be avoided by the action or inaction of the giving-way vessel alone. Were this impending instant in time so evident to everyone there wouldn't be many collisions. How then can one be unjustified in taking action at 2 or 3 or any number of miles off if for a long period the other vessel has done little or nothing (otherwise the collision relative motion would not have persisted), and the turn reduces the relative speed, and causes the predicted relative movement direction to move ahead (with respect to the altering 'privileged' vessel) ? I should have advised the reader that this would not be strictly in accordance with Rule 2 r. I maintain, however, that just waiting for that unknown moment of 'immediate danger' must lead to more problems than it avoids. We do not hear about the accidents that didn't happen when somebody turned away, but we can read volumes about those who tested their vessel and judgment in extremis. 